\title{
Treadmill test in hypothyroidism
}

\author{
Nigam $\mathbf{P}^{1}$, Baghel PK ${ }^{2}$ \\ ${ }^{1}$ Dr Pradeep Nigam, Assiatant Professor, Department of Medicine, S S Medical college, Rewa, MP, India, ${ }^{2}$ Dr P K \\ Baghel, Dr P K. Baghel, Associate Professor, Department of Medicine, S S Medical college, Rewa, MP, India
}

Address for correspondence: Dr. Pradeep Nigam, Email: sonalpragalbh@gmail.com

\begin{abstract}
Introduction: Thyroid hormone has a profound effect on a number of metabolic processes in virtually all tissues, with the heart being particularly sensitive to its effects. The hypothyroidism leads to increased body weight, hyperlipidemia and hypertension are the risk factors for coronary artery disease. Material and Methods: The hypothyroid patients were subjected to tread mill test and other required tests and results analyzed statistically. Results: tread mill test was positive in females more with history of previous risk factor for CAD and resting ECG changes with sedentary life style and tobacco addiction. Conclusion: Hypothyroidism is a definite risk factor for ischemic heart disease and exercise stress testing can help in early detection of occult coronary artery disease.
\end{abstract}

Key words: Thyroid hormone, Treadmill test, hypothyroidism.

\section{Introduction}

Hypothyroidism and cardiac disease have been associated for almost a century now. In 1918, 'Zondek'[1] introduced the term 'myxedema heart', referring to pericardial effusion, ventricular dilatation and hypertrophy, and interstitial edema with swelling of myocardial fibres. Thyroid hormone has a profound effect on a number of metabolic processes in virtually all tissues, with the heart being particularly sensitive to its effects. Thyroid dysfunction can produce dramatic cardiovascular effect, often mimicking primary cardiac disease. Additionally, hypothyroidism which leads to increased body weight, hyperlipidemia and hypertension are the risk factors for coronary artery disease. The treadmill test is presently the most simple, least expensive and fairly sensitive non invasive screening test for the early detection of latent ischemic heart disease. Tread mill exercise electrocardiography has been advocated as simple non-invasive modality to screen asymptomatic individuals, who are considered at high risk for coronary artery disease Froelicher V.F. et al however this has been criticized for its limitations in the diagnosis of coronary disease, especially in asymptomatic persons, minor ST segment changes during testing may not be diagnostic, suggesting only a probability in the continuing spectrum of risk [2]. However it is the non-invasive test which has been shown to have a high predictive value if strongly positive, especially when combined with other

Manuscript received: $12^{\text {th }}$ Jan 2016

Reviewed: $22^{\text {nd }}$ Jan 2016

Author Corrected: $02^{\text {nd }}$ Feb 2016

Accepted for Publication: 12 $2^{\text {th }}$ Feb 2016 parameters. The positive tests with ST segment depression of $2 \mathrm{~mm}$ or more usually indicate definite evidence of coronary artery disease. In present study thirty seven patients having subclinical or clinical hypothyroidism, were subjected to treadmill test and out of these 37 patients, 9 patients $(24.32 \%)$ were found positive for stress test.

\section{Material and Methods}

The patients above age 20 years with confirmed cases of hypothyroidism with clinical features and thyroid profile suggestive of hypothyroidism including both the new patients and old diagnosed patients not on regular hormone replacement therapy for last 6 months without prior history of any kind of coronary artery disease before the diagnosis of hypothyroidism attending OPD between July 2009 to June 2010 were included in this study. The confirmation of hypothyroidism was done by serum $\mathrm{TSH}$, Free $\mathrm{T}_{3}$ and Free $\mathrm{T}_{4}$, level estimation. Christian Meier, Peter Trittibach et al [3]. TSH level was used for assessment of severity of hypothyroidism (Normal values are from 0.4 to $4.0 \mathrm{mIU} / \mathrm{L}$ ). The TSH level between 0.3 and $3.0 \mathrm{mIU} / \mathrm{L}$ was considered as marker for adequate treatment. TSH was measured clinically by competitive binding Radioimmunoassay (RIA). Patients were subjected to TMT on Mortara Xscribe Computerized Stress Test System after all precautions and informed consent[4] 


\section{Results}

In our study maximum belonged to age group of 31 to 50 years $(64.86 \%)$ but incidence of positive stress test was higher in 51 to 70 years age group (66.66\%) (table no.1) and most of them were females with none of the male patient was found to be positive for stress test (table no.2). Though the Hindus (78.73\%) were predominant in the study but positive results for stress test were more with Muslims (57.14\%) compared to Hindus (17.27\%) (table no.3) . In study group most of the cases belonged to middle socioeconomic status $(91.89 \%)$ and urban domicile $(64.86 \%)$ with positive results for stress test more with same socio-economic strata. The most cases had average life style (83.78\%) but had the stress test was maximum positive with sedentary life style (60.00\%). The tobacco addicts had positive TMT (28.57\%) as compared to non tobacco addict $(23.33 \%)$ patients who were. The patients having past history of hypertension with hypothyroidism had more positive stress test $(33.33 \%)$ compared to normotensive $(20 \%)$ (Table no.4) . The cases that were having family history of coronary artery disease, hypertension or diabetes mellitus were very much susceptible for positive results of stress test $(42.10 \%)$. The patients having family history of CAD were more susceptible for positive stress test $(66.66 \%)$, followed by hypertension and diabetes mellitus. The cases having BMI $>30 \mathrm{~kg} / \mathrm{m}^{2}$ had higher incidence of positive stress test $(40.00 \%)$. The patients with resting systolic B.P. of more than $120 \mathrm{~mm}$ of $\mathrm{Hg}$ and diastolic B.P more than $86 \mathrm{~mm}$ of $\mathrm{Hg}$ had more positive stress test (31.57\%) compared to patients with systolic B.P. was less than 120 and diastolic BP below $86 \mathrm{~mm} \mathrm{Hg}$. The positive stress test was more (55.55\%) in the patients whose serum LDL level was more than 100 $\mathrm{mg} / \mathrm{dl}$ as compared to patients whose serum LDL level was less than $100 \mathrm{mg} / \mathrm{dl}$. The cases that were having duration of illness more than 5 years were more susceptive for positive stress test (40\%), as compared to those who had duration of illness $<5$ years $(18.51 \%)$. The patients with symptoms related with cardiac pathology had more stress test positive $(70 \%)$ with breathlessness $(37.83 \%)$ as predominant symptoms followed by chest pain (27.02\%) (Table no.5). The $28.28 \%$ of patients with positive TMT had non-specific ST-T changes in the resting ECG. The low voltage complexes were seen in $32.43 \%$ of cases of which $28 \%$ had positive TMT. The patients with TSH level $>10 \mu$ IU $/ \mathrm{ml}$ were more susceptible for positive stress test $(28 \%)$ as compared to patients who had TSH level $<10 \mu \mathrm{IU} / \mathrm{ml},(16.66 \%)$. In 9 patients who had left ventricular hypertrophy, 3 patients $(33.33 \%)$ were positive for TMT and in 19 patients who had pericardial effusion 5 patients $(26.31 \%$ ) were positive for TMT (table no.6). Only 5 patients had diastolic dysfunction in their echocardiographic study and among them only one case was positive for TMT. The most patients showed normal BP response during TMT $(86.48 \%)$ and none had hypotensive response and also the positive TMT was more with normotensives. The fatigue was the most frequent $(59.45 \%)$ followed by the combination of the both fatigue and THR achievement $(29.72 \%)$ criteria for termination of test and those who could achieve target heart rate $85-100 \%$, showed higher $(28.57 \%)$ positive TMT as compared to patients who could achieve less than $85 \%$ or more than $100 \%$ of target heart rate. Patients were divided into two groups for exercise tolerance according to stages of TMT by Bruce protocol. The patients who did not complete stage 3 i.e. could not exercise upto 9 minutes were kept in one group, and the patients who completed stage 3 i.e. could exercise more than 9 minutes were kept in second group. Most of the cases, 29 out of $37(78.37 \%)$, could not complete stage 3 of TMT, all 9 patients that exhibited positive TMT belonged to same group (table no.7).Only 8 patients completed stage 3 of TMT without showing positive results of stress test. The positive stress tests were more in those who could achieve work load of 6-10 METs though the most patients could achieved >6 met of work load (table no.8) .

Table No 1: Showing age wise distribution of hypothyroid patients and relation with positive TMT

\begin{tabular}{|l|l|l|l|l|}
\hline \multirow{2}{*}{ Age Group } & \multicolumn{1}{|c|}{ No. of pt. } & \multicolumn{1}{|c|}{ +ve } & \multicolumn{1}{c|}{ TMe } & TMT \\
& & & & of +ve Results \\
\hline $20-30 \mathrm{yr}$. & $07(18.91 \%)$ & - & 07 & - \\
\hline $31-50 \mathrm{yr}$. & $24(64.86 \%)$ & 05 & 19 & 20.83 \\
\hline $51-70 \mathrm{yr}$. & $06(16.21 \%)$ & 04 & 02 & 66.66 \\
\hline Total & 37 & 09 & 28 & 24.32 \\
\hline
\end{tabular}


$\chi^{2}=8.253, \mathrm{p}=0.016$, Significan Incidence of positive stress test was higher in age group of 51 to 70 years

Table No 2: Showing sex wise distribution of hypothyroid patients and relation with positive TMT

\begin{tabular}{|l|l|l|l|l|}
\hline Sex & No. of pt. & +ve TMT & -ve TMT & \% of +ve Results \\
\hline Male & $05(13.51 \%)$ & - & 05 & - \\
\hline Female & $32(86.48 \%)$ & 09 & 23 & 28.12 \\
\hline Total & 37 & 09 & 28 & 24.32 \\
\hline
\end{tabular}

$\mathrm{z}=2.29$, Significant Most of the cases were female and all the cases that were positive for stress test were female , none was male

Table No 3: Showing religion wise distribution of hypothyroid patients and relation with positive TMT

\begin{tabular}{|l|l|l|l|l|}
\hline Religion & No. of pt. & +ve TMT & -ve TMT & \% of +ve Results \\
\hline Hindu & $29(78.37 \%)$ & 05 & 24 & 17.24 \\
\hline Muslim & $07(18.91 \%)$ & 04 & 03 & 57.14 \\
\hline Christian & $01(2.70 \%)$ & - & 01 & - \\
\hline Total & 37 & 09 & 28 & 24.32 \\
\hline
\end{tabular}

$\chi^{2}=4.788, p=0.02$, Significant (Between Hindu \& Muslim) Maximum patients were Hindu but positive results for stress test were more with Muslims as compared to Hindus

Table No 4: Showing distribution according to family history of CAD, Hypertension and Diabetes mellitus among hypothyroid patients and relation with positive TMT

\begin{tabular}{|c|c|c|c|c|}
\hline Family history & No. of pt. & +ve TMT & -ve TMT & $\%$ of +ve Results \\
\hline $\begin{array}{l}\text { Family History of } \\
\text { CAD/DM/HTN }\end{array}$ & $\begin{array}{l}19 \\
(51.35 \%)\end{array}$ & 08 & 11 & 42.10 \\
\hline a. CAD & 06 & 04 & 02 & 66.67 \\
\hline b. HTN & 12 & 05 & 07 & 41.66 \\
\hline c. DM & 10 & 04 & 06 & 40.00 \\
\hline \multicolumn{5}{|c|}{$\chi^{2}=1.264, P=0.53$, Not Significant } \\
\hline No family history & $\begin{array}{l}18 \\
(48.65 \%)\end{array}$ & 01 & 17 & 5.55 \\
\hline \multicolumn{5}{|c|}{$\begin{array}{l}\chi^{2}=6.70, p=0.009, \text { Significant between groups having family history and not having family history of CAD, DM, } \\
\text { HTN. }\end{array}$} \\
\hline
\end{tabular}

Patients having family history of CAD, HTN or DM were more susceptible for positive results of stress test as compared to those without 
Table No 5: Showing incidence of positive TMT in hypothyroid patients in relation to symptoms of CAD before TMT

\begin{tabular}{|c|c|c|c|c|}
\hline Symptoms & No. of pt. & +ve TMT & -ve TMT & \% of +ve Results \\
\hline Chest pain & $10(27.02 \%)$ & 04 & 06 & 40.00 \\
\hline Breathlessness & $14(37.83 \%)$ & 03 & 11 & 21.42 \\
\hline Total & $24(64.86 \%)$ & 07 & 17 & 70.00 \\
\hline No symptoms of CAD & $13(35.14 \%)$ & 02 & 11 & 15.38 \\
\hline & 37 & 09 & 28 & 24.32 \\
\hline
\end{tabular}

$\mathrm{Z}=3.98$, Significant between patients having symptoms of CAD and patients without symptoms of CAD.

Pericardial effusion was the most frequently detected abnormalityfollowed by left ventricular hypertrophy.

Table No 6: Showing correlation between Echocardiographic left ventricular hypertrophy, pericardial effusion and diastolic dysfunction with positive TMT

\begin{tabular}{|l|l|l|l|l|l|l|}
\hline \multicolumn{2}{|l|}{ Echo-Changes } & No. of pt. & +ve TMT & -ve TMT & $\begin{array}{l}\text { \% of +ve } \\
\text { Results }\end{array}$ \\
\hline $\begin{array}{l}\text { Left Ventricular } \\
\text { Hypertrophy }\end{array}$ & Present & $09(24.32 \%)$ & 03 & 06 & 33.33 \\
\cline { 2 - 6 }$\chi^{2}=0.52, p=0.46$, Not Significant & 28 & 06 & 22 & 21.42 \\
\hline \multirow{2}{*}{\begin{tabular}{l} 
Pericardial effusion \\
\cline { 2 - 6 }
\end{tabular}} & Present & $19(51.35 \%)$ & 05 & 14 & 26.31 \\
\hline$\chi^{2}=0.08, p=0.77$, Not Significant & 18 & 04 & 14 & 22.22 \\
\hline
\end{tabular}


Table No 7: Showing correlation between exercise tolerances with positive TMT in hypothyroid patients

\begin{tabular}{|l|l|l|l|l|}
\hline Exercise tolerance & No. of pt. & +ve TMT & -ve TMT & \% of +ve Results \\
\hline$\leq 9$ min. & $29(78.37 \%)$ & 09 & 20 & 31.03 \\
\hline$>9$ min. & $08(21.62 \%)$ & - & 08 & - \\
\hline Total & 37 & 09 & 28 & 24.32 \\
\hline
\end{tabular}

$\mathrm{z}=3.61$ Significant Maximum patients could exercise for 9 minutes and completed stage 3 of TMT. All the cases that were positive for stress test belonged to the group of patients that were unable to perform their exercise more than 9 minutes and this difference was significant statistically.

Table No 8: Showing correlation between maximum work load attained by the hypothyroid patients and positive TMT

\begin{tabular}{|l|l|l|l|l|}
\hline Max. Work Load & No. of pt. & +ve TMT & -ve TMT & \% of +ve Results \\
\hline $8-10$ METs & $17(45.95 \%)$ & 02 & 15 & 11.76 \\
\hline $6-8$ METs & $16(43.24 \%)$ & 06 & 10 & 37.50 \\
\hline 3-6 METs & $04(10.81 \%)$ & 01 & 03 & 25.00 \\
\hline Total & 37 & 09 & 28 & 24.32 \\
\hline
\end{tabular}

$\chi^{2}=2.97, p=0.08$, Not Significant.

Most of the patients had achieved $>6$ METs of work load, and positive stress tests was more in the group who could achieve work load of 6-10 METs

\section{Discussion}

It is mentioned that hypothyroidism occurs from birth to old age. However most patients of adult hypothyroidism were seen between age of 30 to 60 years. However mean age of diagnosis of autoimmune hypothyroidism was 60 years and the incidence increased as age increased.

The TMT was more positive in patients of age greater than 50years. All patients with positive stress were female with none being male. The result was statistically significant but the small size of sample limits its usefulness. The case control study done on Nepalese population by Rajendra KC et al[5] in 2015 has average age of $42.23 \pm 11.15$ and $38.6 \pm 10.07$ for serum TSH $<10$ and $\geq 10$ respectively with female predominance. The study by Flynn, Mac Donald et al[6] in 2004 showed that along with incidence and prevalence, the sex ratio also varies with geographic distribution. Though the ischemic heart disease is more common in males but in present study all TMT positive cases were female and statistically this difference was significant, because most hypothyroid patients were female. Also the most were obese and had poor exercise tolerance. A study by Ahmad et al[7] in 2005 shows that there is evidence of increasing prevalence of CAD mainly in women in India. In our study muslims had more positive TMT which was statistically significant but the study sample being small, the results may not show the true picture. Gopinath[8] reported on the asymptomatic Delhi population by religious group, Muslim experienced the highest rates (95/1000) with no cases in Christians. Hindus and Sikhs had similar rates (50 out of 1000 and 54 out of 1000 respectively). We found more tobacco chewing in muslim females which be the cause for above result. In addition prevalence of illiteracy and sedentary life style were significantly more in Muslims, Gupta et al[9]. In the present series, most patients belonged to middle class with none 
belonging to upper socio-economic class. All the hypothyroid TMT positive cases belonged to middle class. Statistically data shows significant difference in both the groups but being a small sample size these figures may not be true enough. R. B. Singh et al[10] studied 1767 subjects of different socio economic status and found that prevalence of coronary artery disease was significantly higher among high and middle socioeconomic groups as compared to low income group. The higher incidence of positive stress test was found with the hypothyroid patients adopting sedentary life style which was insignificant statistically. Morris et al[11] studied 16,882 male civil servants in Britain with active and sedentary life styles concluded that coronary artery disease was more common in people leading a sedentary life.

The reason for higher incidence of hypothyroidism in urban areas may be due to increased awareness and easier accessibility of the urban people to the health care facilities in our setup, supported by Gupta et al[12] (1995) and Chadha et al[13] in 1997 found the overall prevalence of coronary artery disease in adults was 96.7 per 1000 and 27.1 per 1000 in urban and rural population, respectively. The sedentary life style and alcohol intake is significantly $(\mathrm{p}<0.01)$ higher in urban population compared to the rural subjects (R.B. Singh et al[10] 1997) which are the important risk factors for CAD. Our study showed more positive stress test in tobacco chewers but the result was insignificant statistically probably due to small samples size. Shrivastava et al[14] found $41 \%$ positive TMT in smokers and tobacco chewers in comparison to $11.5 \%$ in non-tobacco users. Jaiswani[15] found $26 \%$ positive TMT in tobacco chewers in comparison in $8 \%$ in nontobacco users.

The more of patients in our study with positive stress test had past history of hypertension though the result was statistically insignificant.Abdu et al [16] in their study found a linear positive association between TSH and systolic and diastolic blood pressure within the reference range $(0.50-3.5 \mathrm{mU} / \mathrm{L})$ suggesting that the TSH concentration may have a long-term influence on the cardiovascular condition. According to Saito et al [17] (1983) out of 477 female hypothyroid hypertensive patients 169 were hypothyroid (54.8\%) and adequate thyroid hormone replacement therapy for an average of 14.8 months in 14 patients resulted in a normalization of thyroid function and a reduction of blood pressure $(p<0.01)$. It is well known that family history of CAD, hypertension and diabetes mellitus is a significant risk factor for ischemic heart disease, so was in our study. The patients having family history of CAD had more positive TMT followed by diabetes mellitus and hypertension. Further the patients that were having combination of these factors as a family history posed even more chances of positive results. The maximum chances were with the combination of CAD and hypertension followed by combination of CAD and DM and hypertension and DM.

The positive results of TMT were more with the patients having BMI $>30 \mathrm{~kg} / \mathrm{m}^{2}$ followed by those who had their BMI between $25-30 \mathrm{~kg} / \mathrm{m}^{2}$. The observation was statistically insignificant. The findings of present study are in comparison with the observation of Framingham Heart study [18] which had confirmed obesity as one of the independent risk factors in the genesis of coronary artery disease. Gupta et al [12] in 1995 studied 2212 adults of 20 years of more age, observed coronary risk factors in $11 \%$ of obese adults whose BMI was more or equal to $27 \mathrm{~kg} / \mathrm{m}^{2}$. Also the Ramchandran et al [19] in 1998 by studying 953 subjects showed that the prevalence of obesity as a risk factor of CAD was more as compared to hypertension. Though statistically insignificant, the maximum of TMT positive cases had resting systolic BP between 121 to $140 \mathrm{~mm}$ of $\mathrm{Hg}$ and diastolic BP between 86 to $100 \mathrm{~mm} \mathrm{Hg}$. The study by R. Luboshitzky[20] and colleagues conducted in Israel observed higher diastolic BP in hypothyroidism similar to our study. According to Saito [17] individuals with mild to moderate hypothyroidism have an increased possibility of development of diastolic hypertension, whereas individuals with severe hypothyroidism are more likely to have normal or slightly low blood pressure. The increased level of serum LDL and triglycerides in hypothyroid patients correlates with higher chance of hidden coronary artery disease. The correlation of serum lipoprotein level and positive results of TMT in hypothyroid patients may not be true enough and significant statistically due to small sample size. Study by Sharma et al [21] also demonstrated that patients with subclinical hypothyroidism had significantly higher levels of serum hs-CRP, Lp (a), total cholesterol, and LDL-C when compared to same parameters of controls. Roos et al [22] (2005) had done bicycle ergometry and dobutamine stress echocardiography of 51 cardiac asymptomatic hypothyroid patients and

was found that HDL cholesterol was lower and triglyceride were higher but he did not get any positive result for bicycle ergometry. According to Giral et 
al[23] a positive exercise electrocardiogram is not infrequent occurrence in asymptomatic hypercholesterolemic patients, but the number of false positive tests may be relatively high (50\%). Although not significant our study showed that chances of ischemic heart disease increases with the duration of illness. According to 10 case reports on coronary artery disease in hypothyroidism by Ben Ameur [24], during the course of hypothyroidism coronary lesions were more extended, complex and severe.

The positive results for TMT, was maximum with patients who had complaints of chest pain followed breathlessness before TMT. This observation was quite significant statistically. In nearly 11000 patients undergoing stress testing at the Cleveland clinic, dyspnea was the presenting symptoms in $8 \%$ of cases, and the outcome among patients with dyspnea was similar to that among patients with typical angina (Christophes et al) [25]. According to Bergeron et al [26] study dyspnea is a predictor of an adverse outcome in patients with known or suspected coronary artery disease who are undergoing stress testing. According to Bodegard et al [27], the presence of atypical chest pain indicates a low probability of CAD, moreover even in the absence of chest pain, the presence of symptoms such as dyspnea may serve as an angina equivalent or a marker of underlying cardiac disease. It was also observed that positive results for TMT were also more with those who had ST-T changes in their resting ECG which was statistically significant. In a study by Kansal et al [28], near maximal graded exercise tests and coronary angiograms were compared in 37 patients with a history of chest pain and with ST segment depression at rest, who were free of obvious non-ischemic causes of ST depression. Additional ST depression of $0.1 \mathrm{mV}$ or more occurred with exercise in 26 patients and, 23 of these had obstruction of one or more coronary arteries.

In present study positive TMT were more with the patients having clinical hypothyroidism $(\mathrm{TSH}>10 \mu$ $\mathrm{IU} / \mathrm{ml}$ ) as compared to patients having subclinical hypothyroidism (TSH $<10 \mu \quad \mu \quad \mathrm{IU} / \mathrm{ml}$ ) which was insignificant statistically. A study by Shams et al [29] in 2005 revealed $6.4 \%$ of subclinical hypothyroidism patients and was not associated with a higher frequency or greater severity of CAD. The mean serum thyrotropin level was significantly higher in women. There was neither correlation between serum thyrotropin and presence of CAD nor with the extent of CAD. Although the predominant finding was pericardial effusion on 2d-echocardiography, the stress test was more positive in patients with left ventricular hypertrophy compared to pericardial effusion and diastolic dysfunction, the results was insignificant statistically. According to Rechard's [30] study (1975) on 33 hypothyroid patients by echocardiography $30 \%$ had positive echo for pericardial effusion. Bernadette et al [31] studied 26 patients and 30 normal control subjects by means of doppler echocardiography and demonstrated that abnormal left ventricular diastolic filling (suggestive of impaired left ventricular relaxation) is a common finding in patients with subclinical hypothyroidism.

In present study normal blood pressure response was observed in the most of the persons during TMT. Also the TMT were more positive in patients that were showing normotensive response during TMT Dubach et al [32] (2005) after studying 2036 patients by treadmill test revealed exercise induced hypotension, which was significantly associated with increased risk for cardiac events but none exhibited hypertensive response. Because of small sample size we could not formulate any correlation between positive TMT and blood pressure response, and statistically observation found to be insignificant.

In present study, reason for termination of TMT in most of the cases was fatigue followed by achievement of their target heart rate along with the fatigue. A few had hypertensive response and achievement of target heart rate during TMT. In this study most of the patients were of age less than 50 years and therefore many of them are able to exercise efficiently. The TMT was relatively more positive in those whom the termination of TMT was done for both fatigue and target heart rate achievement. The $78.37 \%$ of the cases could not complete stage 3 of TMT and all the patients that exhibited positive TMT completed stage 3 bruce protocol. This observation was found to be statistically significant, though sample size was quite small. The study by Roos and Zoet-Nugteren[33] in 2005 revealed exercise tolerance which was insufficient in $38 \%$ of hypothyroid patients (performance of $77 \pm 8 \%$ of target) and normal in $62 \%$ of hypothyroid patients (performance of $110 \pm 13 \%$ of target). In this study, most of the patients $(89 \%)$ could achieve more than 6 met of work load, and therefore all the TMT positive cases were included in this group. Statistically there was no correlation found between positive TMT and attainment of maximum work load.

\section{Conclusion}


It can be concluded that hypothyroidism is a definite risk factor for ischemic heart disease and exercise stress testing can well be used to detect occult coronary artery disease. The screening with treadmill stress test should be carried out particularly in those who are having long duration of illness of hypothyroidism along with chest pain, breathlessness and/or non-specific ST-T changes in their resting ECG, for early detection of occult coronary artery. The patients of hypothyroidism having positive stress test and are symptomatic, should be subjected to coronary artery revascularization therapy.

\section{Funding: Nil}

Conflict of interest: None.

Permission of IRB: Yes

\section{References}

1. Zondek H; Das myxödemherz. München Med Wehnsch 1918; 2:1180-2. 2.

2. Froelicher VF Jr, Wolthius R, Keiser N, Stewart A, Fischer J, Longo MR Jr, Triebwasser JH, Lancaster MC. A comparison of two bipolar exercise electrocardiographic leads to lead V5. Chest. 1976 Nov;70(5):611-6.

3. Christian Meier, Peter Trittibach, Merih Gugliemetti, Jean Jacques Staub and Beat Muller: TSH in assessment of severity of tissue hypothyroidism in patients with overt primary thyroid failure: Cross sectional survey. B.M.J. 8 Feb 2003;vol. 326.

4. Bruce RA, McDonough JR. Stress testing in screening for cardiovascular disease. Bull N Y Acad Med. 1969 Dec;45(12):1288-305.

5. Kc R, Khatiwada $\mathrm{S}^{2}$, Deo Mehta $\mathrm{K}^{3}$, Pandey $\mathrm{P}^{4}$, Lamsal $\mathrm{M}^{3}$, Majhi $\mathrm{S}^{3}$. Cardiovascular Risk Factors in Subclinical Hypothyroidism: A Case Control Study in Nepalese Population. J Thyroid Res. 2015;2015:305241. doi: 10.1155/2015/305241. Epub 2015 Oct 7.

6. Flynn RW, MacDonald TM, Morris AD, Jung RT, Leese GP. The thyroid epidemiology, audit, and research study: thyroid dysfunction in the general population. J Clin Endocrinol Metab. 2004 Aug;89(8):3879-84.
7. Ahmad N, Bhopal R. Is coronary heart disease rising in India? A systematic review based on ECG defined coronary heart disease. Heart. 2005 Jun;91(6):719-25.

8. Gopinath N, Chadha SL, Jain P, Shekhawat S, Tandon R. An epidemiological study of coronary heart disease in different ethnic groups in Delhi urban population. J Assoc Physicians India. 1995 Jan;43(1):30-3.

9. Gopinath N, Chadha SL, Jain P, Shekhawat S, Tandon R. Hindu-Muslim differences in the prevalence of coronary heart disease and risk factors. J Indian Med Assoc. 2002 Apr;100(4):227-30.

10. Singh RB, Sharma JP and Rastogi V et al. Prevalence of coronary artery disease and coronary risk factors in rural and urban populations of north India. Eur. Heart J. 1997;18: 1728-35.

11. Morris DP; Brunner. Physical activity and coronary artery disease. Joslin's Diabetes Mellitus. 1974; Pg-231.

12. Gupta R, Prakash H, Majumdar S. Prevalence of coronary heart disease and coronary risk factors in an urban population of Rajasthan. Ind.Heart.J. 1995;47:331-8.

13. Chadha SL, Gopinath N, Shekhawat S. Urban-rural differences in the prevalence of coronary heart disease and its risk factors in Delhi. Bull World Health Organ. 1997;75(1):31-8.

14. Shrivastava R, Jain MK, Khanijo SK. Observation on hypertension with special reference to Treadmill test. A thesis of Doctor of Medicine, APS University, Rewa, 1992.

15. W. Jaiswani. T.M.T, in tobacco chewers. A thesis of Doctors of Medicine, APS University, Rewa, 1994.

16. Abdu TA, Elhadd T, Pfeifer M, Clayton RN. Endothelial dysfunction in endocrine disease. Trends Endocrinol Metab. 2001;12: 257-265.

17. Saito I, Ito K, Saruta T. Hypothyroidism as a cause of hypertension. Hypertension. 1983 Jan-Feb;5(1):1125 .

18. Hubert HB, Feinleib M, McNamara PM, Castelli WP. Obesity as an independent risk factor for cardiovascular disease: a 26-year follow-up of participants in the Framingham Heart Study. Circulation. 1983 May;67(5):968-77. 
19. Ramachandran A, Snehalatha C, Latha E, Satyavani $\mathrm{K}$, Vijay V. Clustering of cardiovascular risk factors in urban Asian Indians. Diabetes Care. 1998 Jun;21(6):967-71.

20. R. Luboshitzky, A. Aviv, P. Herer, L. Lavie. "Risk factorsfor cardiovascular disease in women with subclinical hypothyroidism,"Thyroid, 2002; vol. 12, no. 5, pp. 421-425.

21. Sharma R, Sharma TK, Kaushik GG, Sharma S, Vardey SK, Sinha M. Subclinical hypothyroidism and its association with cardiovascular risk factors. Clin Lab. 2011;57(9-10):719-24.

22. A Roos, SK Zoet-Nugteren, A Berghout. Evaluation of cardiac ischemia in cardiac asymptomatic newly diagnosed untreated patients with primary hypothyroidism. The Journal of Medicine (Netherland), March-2005-Vol-63, No- 3.

23. Giral P, Bruckert E, Dairou F, Boubrit K, Drobinski G, Chapman JM, Beucler I, Turpin G. Usefulness in predicting coronary artery disease by ultrasonic evaluation of the carotid arteries inasymptomatic hypercholesterolemic patients with positive exercise stress tests. Am J Cardiol. 1999 Jul 1;84(1):14-7.

24. Ben Ameur Y, Yaacoub A, Haggui A, Terras M, Battikh K, Longo S, Kraiem S, Slimane ML. [Coronary disease in hypothyroidism. 10 case reports]. Tunis Med. 2003 Dec;81(12):944-8.

25.Christopher Jones R, Pothier CE, Blackstone EH, La uer MS.

Prognostic importance of presenting symptoms in patie nts undergoing exercise testing for evaluation ofknown or suspected coronary disease. Am J Med. 2004 Sep 15;117(6):380-9.

\begin{tabular}{|c|c|c|}
\hline 26. Bergeron & S, Ommen & SR, Bailey \\
\hline
\end{tabular}

echocardiographic findings and outcome of patients referred for evaluation of dyspnea. J Am Coll Cardiol. 2004 Jun 16;43(12):2242-6.

27.Bodegard J, Erikssen G, Bjornholt JV, Thelle D, Eri kssen J.

Possible angina detected by the WHO angina questionnaire in apparently healthy me $\mathrm{n}$ with a normal exerciseECG: coronary heart disease or not? A 26 year follow up study. Heart. 2004 Jun;90(6):627-32.

28. Kansal S, Roitman D, Sheffield LT. Stress testing with ST-segment depression at rest. An angiographic correlation. Circulation. 1976 Oct;54(4):636-9.

29. Sham M, Sharif-Kazemi MB, Lankarani KB, Sadegholvad AS, Omrani GR. Are serum thyrotropin level and Subclinical hypothyroidism predisposing factors for coronary artery disease? Int. J. Endocrinol. Metab. 2005;2:67-73.

30. Kerber RE, Sherman B. Echocardiographic evaluation of pericardial effusion in myxedema. Incidence and biochemical and clinical correlations. Circulation. 1975 Nov;52(5):823-7.

31. Bernadette Biondi, Serafino Fazio, Emilliano Antonio Palmieri and Luigi Sacca et al; Left Ventricular diastolic dysfunction in patients with Sub clinical hypothyroidism. J. Clin. Endocrinol and Metab. 1999.

32. Dubach P, Froelicher VF, Klein J, Oakes D, GroverMcKay M, Friis R. Exercise-induced hypotension in a male population. Criteria, causes, and prognosis. Circulation. 1988 Dec;78(6):1380-7.

33. A Roos, SK Zoet-Nugteren, A Berghout; Evaluation of cardiac ischemia in cardiac asymptomatic newly diagnosed untreated patients with primary hypothyroidism. The Journal of Medicine (Netherland). March-2005-Vol-63, No- 3.

\section{How to cite this article?}

Nigam P, Baghel PK Treadmill test in hypothyroidis. Int J Med Res Rev 2016;4(3):338-346. doi: 10.17511/ijmrr.2016.i03.09. 